Int. J. , Vol. x, No. x, $x x x x$

\title{
OPTIMISATION OF ELECTRIC FIELD UNIFORMITY IN MiCROWAVE HEATING SYSTEMS BY MEANS OF MULTI- FEEDING AND GENETIC ALGORITHMS
}

\author{
E. DOMÍNGUEZ-TORTAJADA ${ }^{1}$, P. PLAZA-GONZÁLEZ ${ }^{2}$, A. DÍAZ-MORCILLO ${ }^{1}, \mathrm{~J}$. \\ V. BALBASTRE ${ }^{2}$ \\ elsa.dominguez@upct.es, pedplago@doctor.upv.es, alejandro.diaz@upct.es, \\ jbalbast@dcom.upv.es \\ ${ }^{1}$ Department of Information Technologies and Communications, Technical University of \\ Cartagena, Campus Muralla del Mar s/n, E-30202 Cartagena (Murcia). SPAIN. \\ ${ }^{2}$ Department of Communications, Technical University of Valencia, Camino de Vera $s / n$, \\ E-46022 Valencia. SPAIN
}

\begin{abstract}
In most of microwave heating applications obtaining uniform heating patterns in certain regions of the applicator is a key issue. In this paper, the proposed solution for achieving electric field uniformity consists of designing the configuration of the feeding system in a multimode cavity by means of Genetic Algorithms. The feeding system is constituted by waveguides or slots arrays. The electric field pattern inside the cavity depends on the location of these sources and an improvement in the electric field uniformity on the product can be obtained by means of a proper design of this feeding system. Results for the curing of epoxy resin over a marble slab are presented and they show a significant improvement in the electric field uniformity over the epoxy resin.
\end{abstract}

Keywords: Microwave-Heating Processing, Field Uniformity, Genetic Algorithms, Microwave Industrial Oven, Dielectric Heating

Biographical Notes: E. Domínguez-Tortajada was born in Valencia, Spain, on June 1976. She received the Dipl. Ing. Degree in Telecommunications Engineering in 2001 from the Universidad Politécnica de Valencia, Valencia, Spain. In 2002, she joined the Departamento de Tecnologías de la Información y las Comunicaciones, Universidad Politécnica de Cartagena, Cartagena, Spain, where she is currently an Associate Lecturer. Nowadays, she combines her teaching and researching activities in different areas that cover microwave-assisted heating processes, microwave applicator design and optimisation and numerical techniques in electromagnetics. 
E. Domínguez-Tortajada, P. Plaza-González, A. Díaz-Morcillo, J.V. Balbastre

P. Plaza-González, was born in Elda (Alicante), Spain, on June 1971. He received the Dipl. Ing. Degree in Telecommunications Engineering from the Universidad Politécnica de Valencia, Spain, in 1998. From 1999 he is a Research Assistant with the Microwave Heating Group (GCM) at the Universidad Politécnica de Valencia. His current research areas are focused on microwave-assisted heating and drying processes, microwave power instrumentation and temperature control in microwave power systems. He is currently working on his $\mathrm{PhD}$ degree in these topics.

A. Díaz-Morcillo was born in Albacete, Spain, in 1971. He received the Ingeniero (Ms. Eng.) and Doctor Ingeniero (Ph. D.) degrees in Telecommunication Engineering, both from Polytechnic University of Valencia (UPV), Spain, in 1995 and 2000, respectively. From 1996 to 1999 he was a Research Assistant at the Department of Communications of the UPV, and in 1999 he joined the Department of Information Technologies and Communications at the Polytechnic University of Cartagena (UPCT), Spain, as Teaching Assistant, where he is currently Associate Professor since 2001. He leads the "Electromagnetics and Matter" Research Group at UPCT and his main research interest lays on Numerical Methods in Electromagnetics and Industrial Microwave Heating Systems.

J.V. Balbastre Tejedor was born in Mislata, Spain, in 1969. He received the Ingeniero (Ms. Eng.) and Doctor Ingeniero (Ph. D.) degrees in Telecommunication Engineering both from Polytechnic University of Valencia (UPV), Valencia, Spain, in 1993 and 1996, respectively. In 1993 he joined the Department of Communications at the UPV as Teaching Assistant, where he is currently Associate Professor since 1998. His main research interest lays in numerical methods, Electromagnetic Compatibility and Industrial Microwave Heating Systems.

\section{Introduction}

One of the most important and desired goals in microwave heating processes is the uniformity of the electric field distribution within the irradiated material since the final product quality depends on it. However, this is not an easy task, for both single mode and multimode applicators.

Different methods have been used in order to obtain uniform heating patterns in certain regions. Moving trays or mode stirrers are employed 
Optimisation of Electric Field Uniformity in Microwave Heating Systems by means of Multi-feeding and Genetic Algorithms

within multimode cavities to achieve a uniform absorption of the electric field in the material [1-4]. However, very few works have been reported about uniformity of electric field pattern, mainly due to the fact that this has been carried out by trial and error, personal experience and tradition, which has led to high design costs. Fortunately, the increase of computational power and the application of numerical techniques such as Finite Difference Time Domain (FDTD) can allow to solve large electromagnetic problems such as those considered in industrial microwave heating applications. Additionally, the combination of electromagnetic software with general purpose optimisation techniques has allowed not only to analyse but also to properly design microwave heating applicators.

In this paper an optimisation method of the electric field uniformity based on the multifeeding system design by means of Genetic Algorithms (GA) is presented. GA are stochastic search procedures that manage a population of potential solutions that evolve towards a global optimal solution. This evolution occurs as a result of pressure exerted by a fitnessweighted selection process; exploration of the solution space is accomplished by recombination and mutation of existing characteristics in the current population.

GA have been an especially helpful tool during the last years in electromagnetic design. Previously to this work, several design studies in different areas of electromagnetism have been developed, mainly in antennas and filters design [5-7]. One remarkable application is presented by Pitarch et al. in [8] where uniform electric field distributions in microwave multimode applicators are achieved by obtaining the optimum feed positions by means of a GA and multimodal circuital techniques. In [9] the goal involves maximizing the system matching and minimizing the mutual coupling among the sources in a three dimensional scenario. The 
E. Domínguez-Tortajada, P. Plaza-González, A. Díaz-Morcillo, J.V. Balbastre

best location of the sources in order to achieve this objective is obtained by means of a GA. Other optimisation techniques are frequently applied in the design of microwave heating systems, such as the constrained optimisation used in [10] or neural networks [11].

In this work, the applicator consists of a rectangular cavity loaded with marble and epoxy resin. In order to obtain a heating uniformity over the resin during the curing process, two feeding scenarios are considered: multiple waveguide feeding and slotted waveguide feeding. The electric field uniformity is analysed from a statistical criterion such as the standard deviation normalized to the average electric field in the sample. In order to implement the GA, an in-house MATLAB ${ }^{\circledR}$ code based on [12] is used.

\section{Problem Description}

Two different approaches to the problem are considered depending on the feeding system. First, for multiple waveguides, a two-dimensional (2D) analysis has been performed by means of the MATLAB ${ }^{\circledR}$ Partial Differential Equations Toolbox, where the problem is solved using the Finite Element Method (FEM). In this approach only $\mathrm{TE}_{\mathrm{mn} 0}$ and $\mathrm{TM}_{\mathrm{mn} 0}$ are considered. Nevertheless, it is useful for validating the optimisation procedure and for obtaining information about the behaviour of the evolutionary algorithm. The results of a 2D model constitute a particular unrealistic solution of a three-dimensional (3D) model where one dimension is considered invariant, and with them, a preliminary evaluation of the system performance can be quickly obtained because of the low computational cost of the $2 \mathrm{D}$ approach as regards to the $3 \mathrm{D}$ one at the fullwave simulation stage.

A 3D optimisation procedure has been employed for slotted waveguide feeding. In this case, a commercial electromagnetic simulation tool (CST 
Optimisation of Electric Field Uniformity in Microwave Heating Systems by means of Multi-feeding and Genetic Algorithms

Microwave Studio 5), based on Finite Integration Technique (FIT), has been used.

For both cases, the applicator is a $320 \mathrm{~mm}$ cubic cavity, the marble is modelled by a $100 \mathrm{~mm}$ × $100 \mathrm{~mm}$ × $20 \mathrm{~mm}$ slab with a relative electric permittivity $\varepsilon_{r}=7.9-j 0.1$, and the epoxy resin is a $100 \mathrm{~mm} \mathrm{x} 100 \mathrm{~mm} \mathrm{x}$ $3 \mathrm{~mm}$ slab $\left(\varepsilon_{r}=3.8-j 0.92\right)$. These samples are located on a PTFE tray with $5 \mathrm{~mm}$ thickness. The multiple waveguide feeding system consists of WR340 waveguides located in the different faces of the applicator, and the slotted waveguide with a variable number of slots is located in the centre of the upper side. Both waveguides are excited with the $\mathrm{TE}_{10}$ mode. Figures 1 and 2 depict the arrangement of the problem for $2 \mathrm{D}$ and $3 \mathrm{D}$ scenarios, respectively.

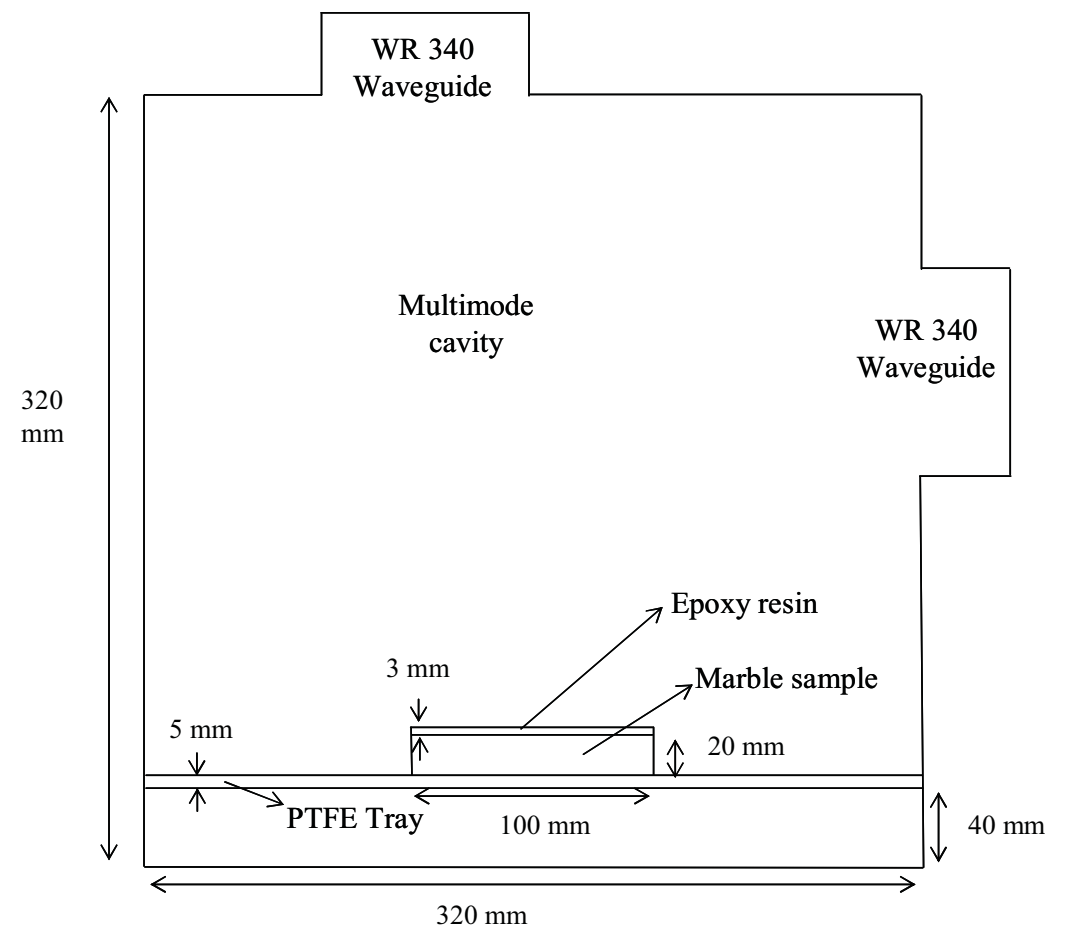

Figure 1. Geometry of the problem arrangement for 2D approach (example of 2 waveguide feeding) 


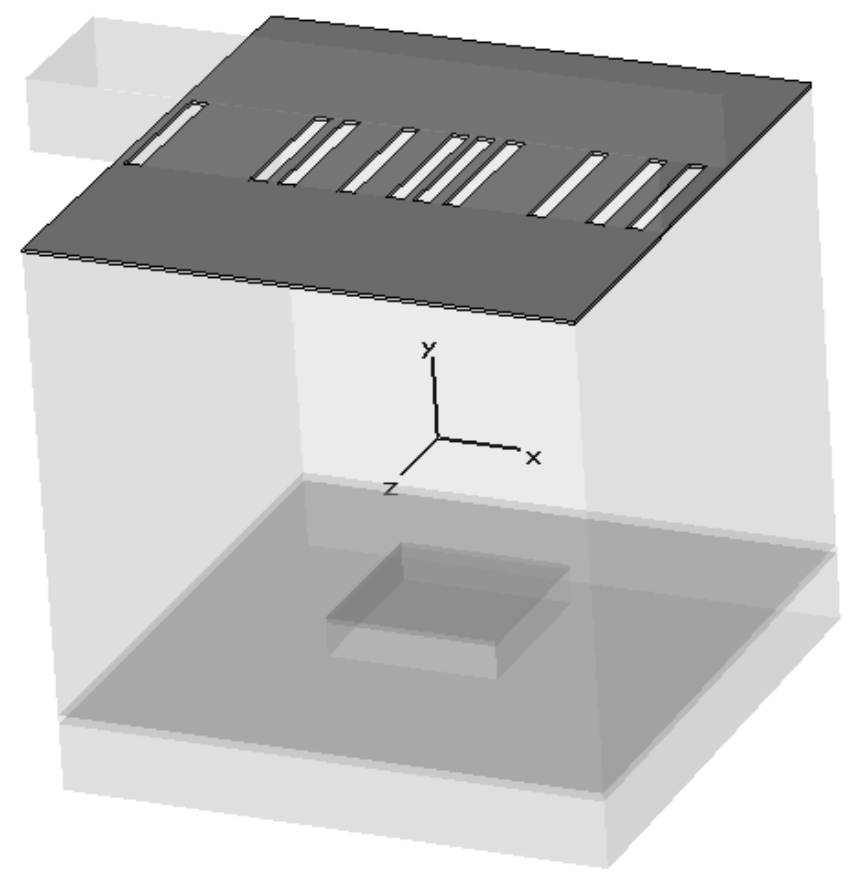

Figure 2. Geometry of the problem arrangement for 3D approach (slotted waveguide feeding)

The optimal location of the waveguides, for the first case, or the optimum location of the slots, for the second one, is the objective that GA must accomplish in order to achieve uniform electric field over the epoxy sample. Other parameters, as waveguide orientation or slot orientation and thickness, can be easily added in the algorithm.

The electric field uniformity in the sample must be maximized and, therefore, the evaluation function that GA must minimize is the standard deviation of the electric field in the sample surface. Moreover, this quantity is normalized by the mean value of the electric field strength (1) in the sample surface in order to obtain high electric field values on that zone. Consequently, the normalized standard deviation considers two 
Optimisation of Electric Field Uniformity in Microwave Heating Systems by means of Multi-feeding and Genetic Algorithms

goals: the minimization of the standard deviation in order to obtain electric field uniformity, and the maximization of the average of this electric field.

$$
\bar{\sigma}=\frac{\sqrt{\frac{\sum_{i=1}^{n}\left(\left|E_{i}\right|-\bar{E} \mid\right)^{2}}{n}}}{|\bar{E}|}
$$

where $n$ is the number of points considered on the upper surface of the sample, $\left|E_{i}\right|$ are the absolute electric field values at each point and $\overline{\mid E} \mid$ is the average of all these values.

It is important to remark that the normalized standard deviation is calculated on the surface of the processed material, but not in all the volume of the product. The electric field undergoes an experimental decay inside the material which depends on its dielectric properties and, therefore, it is difficult to improve by means of a multi-feeding design.

\section{Genetic Algorithms}

The GA is a general optimisation technique with application to a great variety of problems by means of an adequate choice of its parameters and functions. For a perfect control of the logic and the procedures used in these algorithms it is required to establish correctly the suitable requirements for each problem type and to explore the possible enhancements that are appropriate for obtaining the best results.

The GA flowchart used in this work is depicted in Figure 3. It can be observed that the first step involves establishing the design parameters, their range of variation, the number of individuals in each population, and the number of generations, that is, the total number of optimisation iterations to be simulated. The crossover and the mutation probabilities and the considered crossover, mutation and individual selection types are 
also assigned in this initial stage. Once the essential parameters of the algorithm are defined, the first population is randomly created and all the individuals are evaluated through electromagnetic simulations to assign their own fitness. This fitness value is the connection between the physical problem and the GA. Each individual is a combination of design parameters or a solution of the problem. Figure 4 shows the coding of each individual for the considered scenarios.

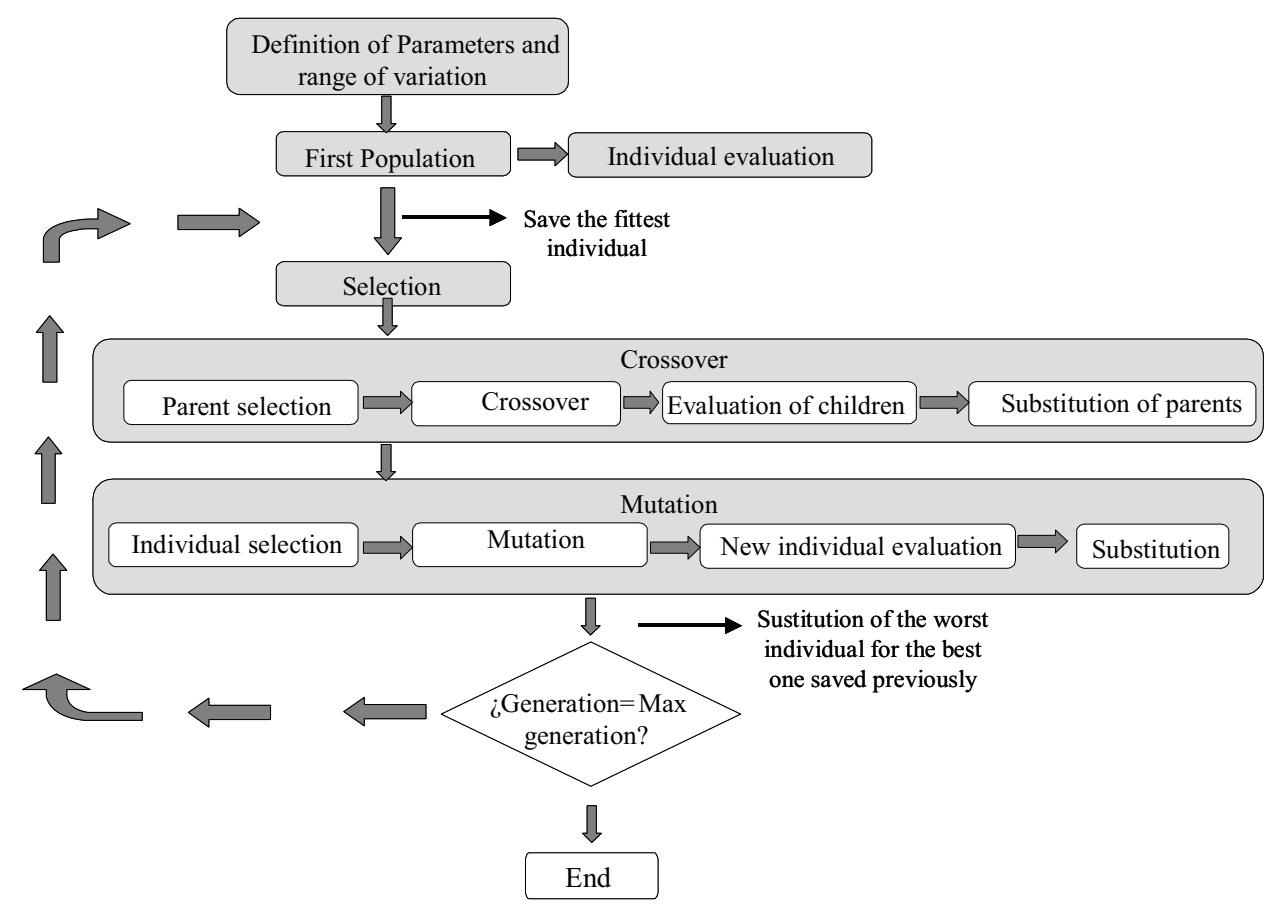

Figure 3. Genetic Algorithm Flowchart 
Optimisation of Electric Field Uniformity in Microwave Heating Systems by means of Multi-feeding and Genetic Algorithms

Waveguides coding

\begin{tabular}{|c|c|c|c|c|}
\hline $\begin{array}{l}\text { Location at } \\
\text { side } 1\end{array}$ & $\begin{array}{l}\text { Location at } \\
\text { side } 2\end{array}$ & $\ldots$ & $\begin{array}{l}\text { Location at } \\
\text { side } n\end{array}$ & $\bar{\sigma}$ \\
\hline
\end{tabular}

Slots coding

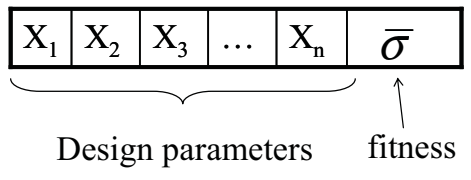

Figure 4. Coding of individual attributes

The fittest individual is saved, in order to preserve the best one in the reproduction process, or during the crossovers and mutations that are performed. Then, a selection of the fittest individuals, the individual's recombination and, finally, the mutation are performed. These two final procedures obtain new individuals that replace the individuals of the present population and must be evaluated as well. After that, the worst individual in the population is substituted by the best one saved previously. In this way, the best design, associated with the best individual, cannot be lost in the optimisation process. The loop finishes when the last generation has been completed.

GA are designed to maximize functions and the objective here involves the minimization of expression (1). For this reason, the evaluation function has been computed as

$$
\text { Fitness }=\bar{\sigma}_{\max }-\bar{\sigma}
$$

where $\bar{\sigma}_{\max }$ is a positive value higher than the maximum value that the function $\bar{\sigma}$ can get. 
E. Domínguez-Tortajada, P. Plaza-González, A. Díaz-Morcillo, J.V. Balbastre

The GA operators (selection, crossover or mutation) are not computationally expensive. Nearly all of the computational cost is due to the fitness evaluation, which requires an electromagnetic simulation for each individual and frequency.

Due to the great number of individuals that must be evaluated, a numerical method with low cost is very important. In a problem with $N$ individuals in each population, $M$ generations, $P_{c}$ probability of crossover and $P_{m}$ probability of mutation, the design time is

$$
T=N \cdot t_{\text {sim }}\left[1+\left(2 P_{c}+P_{m}\right)(M-1)\right]
$$

with $t_{\text {sim }}$ the time for one simulation. MATLAB ${ }^{\circledR}$ PDE Toolbox fulfils the time consumption requirements solving the $2 \mathrm{D}$ design problems included in this article in a maximum of one hour in a Pentium IV 1GB RAM personal computer with Windows XP. For the 3D case, the number of unknowns at each simulation increases substantially and the algorithm requires more time to converge to the final design. Although in this work full - wave simulations have been carried out by means of numerical methods (FEM and FIT), for prismatic shapes of applicator and materials, a more analytic and efficient mode - matching technique could be implemented in order to reduce the computational cost of electromagnetic simulations and to allow a more intensive search in the solution space, that is, a large number of individuals, generations, crossovers and mutations.

\section{Results}

The input power for the $\mathrm{TE}_{10}$ mode excitation of waveguides was set to 1 Watt. For all the designs performed in this work the GA parameters have been set as follows:

- Individuals per generation $=4$

- $\quad$ Number of generations $=10$

- Crossover probability $=10$ 
Optimisation of Electric Field Uniformity in Microwave Heating Systems by means of Multi-feeding and Genetic Algorithms

- Mutation probability $=5$

- Crossover type $=$ arithmetic

- $\quad$ Mutation type $=$ non-uniform

where the crossover probability is defined as the times that the algorithm performs the crossover procedure in each generation and the mutation probability is considered as the times that the algorithm performs the mutation procedure in each generation.

In the multiple waveguide case, different optimisation configurations are evaluated, from the single case of one waveguide up to four waveguides, one per side. Figures 5 and 6 show the final design and the corresponding electric field distribution in the applicator for a one-guide and a fourguides configurations. Comparing these figures, the improvement of the electric field uniformity working with four waveguides is noticeable due to the lower number of lobes near the sample. This improvement is clearer al Figure 7, where the electric field strength at the surface of the epoxy resin, where the uniformity is optimised, is depicted. It can be observed a reduction of the field strength as well. The fitness function considered here to evaluate the designs establishes a compromise between the electric field uniformity and the electric field strength. It is possible to consider other evaluation functions with weighting coefficients in order to outweigh the uniformity or the strength. This is also evident examining Table 1 where information about the normalised standard deviation the electric field strength and the computational times for each case are detailed. 
E. Domínguez-Tortajada, P. Plaza-González, A. Díaz-Morcillo, J.V. Balbastre
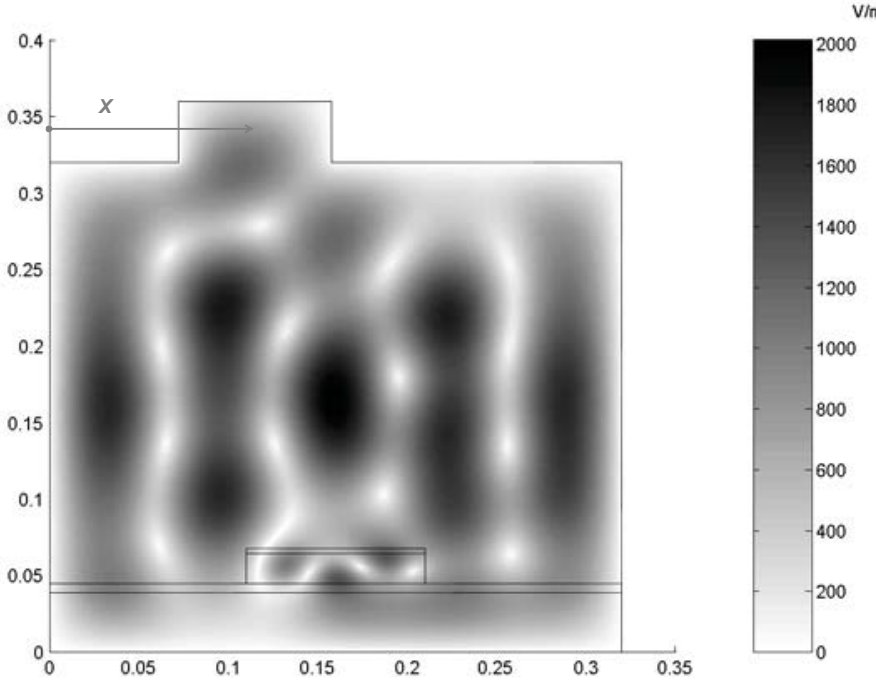

Figure 5. Final design and electric field distribution for one-guide feeding $(X=114.8 \mathrm{~mm}$.
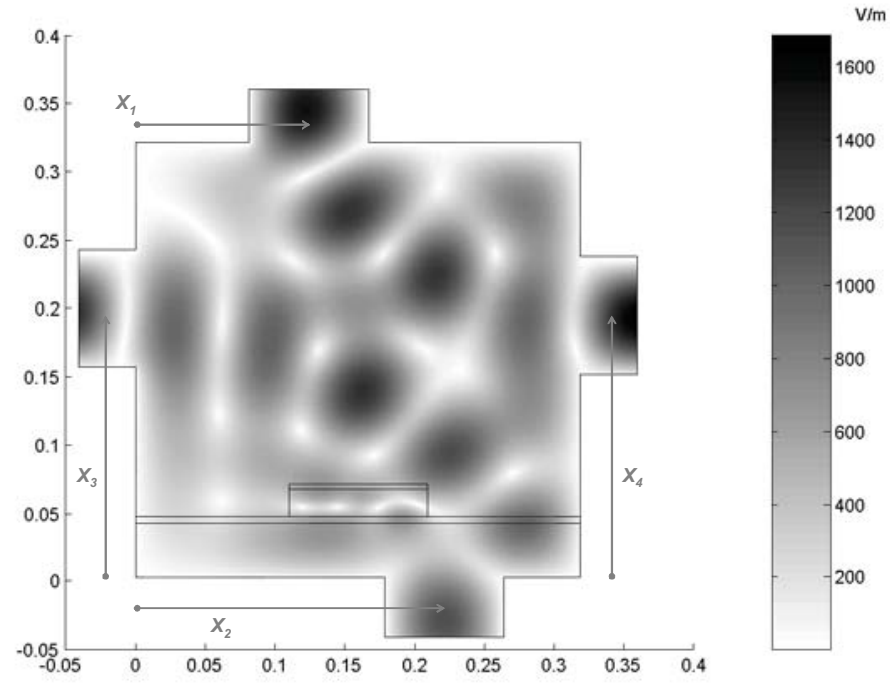

Figure 6. Final design and electric field distribution for four-guides feeding $\left(X_{1}=124.5 \mathrm{~mm}, X_{2}=221.9 \mathrm{~mm}, X_{3}=197.5 \mathrm{~mm}\right.$ and $X_{4}=192.4$ $\mathrm{mm})$ 
Optimisation of Electric Field Uniformity in Microwave Heating Systems by means of Multi-feeding and Genetic Algorithms

Table 1. Statistical results for waveguide feeding

\begin{tabular}{|c|c|c|c|}
\hline Configuration & $\begin{array}{c}\text { Norm. standard } \\
\text { deviation }\end{array}$ & $\begin{array}{c}\text { Electric field } \\
\text { mean }\end{array}$ & $\begin{array}{c}\text { Computational } \\
\text { times }\end{array}$ \\
\hline One waveguide & 0.3648 & $671.2501 \mathrm{~V} / \mathrm{m}$ & $12 \mathrm{~min}$. \\
\hline $\begin{array}{c}\text { Four } \\
\text { waveguides }\end{array}$ & 0.1445 & $574.9951 \mathrm{~V} / \mathrm{m}$ & $21 \mathrm{~min}$. \\
\hline
\end{tabular}

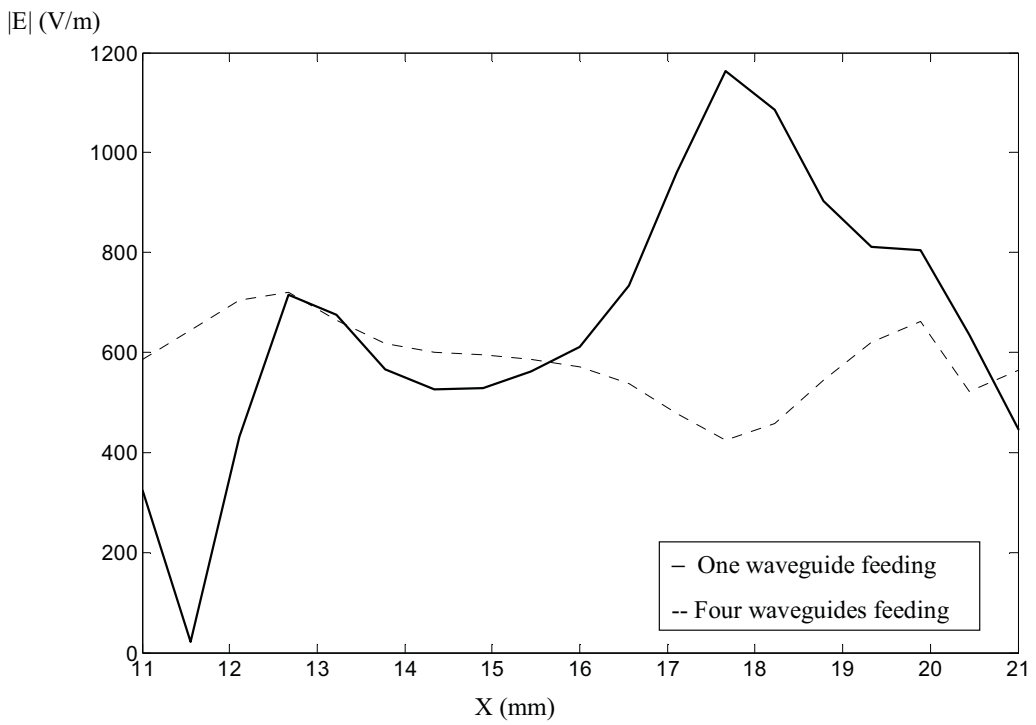

Figure 7. Electric field strength on the surface of the epoxy resin sample.

The evolution of the generations during the optimisation process is presented in Figures 8 and 9 for both cases. In these figures the cross mark indicates the normalized standard deviation for each individual, and the circle marks point out the best individual at each generation. It can be observed that in both cases the last generation presents individuals with a similar fitness, which is a typical behaviour of GA if the mutation probability is bounded to a small or medium value. 
The GA evolution for the case with one waveguide is represented in Figure 8 and shows the optimisation reached along the generations. It can be noticed that the value of the normalized standard deviation is minimized improving the electric field uniformity in the sample and the heating process. To prove that the design obtained with the GA is the optimum result, an iterative procedure was executed. In this analysis the feeding waveguide changes its location with steps of $5 \mathrm{~mm}$ in the upper side of the applicator and the normalized standard deviation is calculated for every position. The best result corresponds to $X=115 \mathrm{~mm}$. for the iterative method and $\mathrm{X}=114.8 \mathrm{~mm}$ for the GA technique. In the case of four waveguides, the solution space is much larger than the one waveguide case and the convergence is slightly slower (Figure 9).

The key feature here is that GA is a global optimisation technique and it guarantees an optimised result non-dependent on the initial guess. In order to avoid too slow convergences it is necessary a checking period to adjust parameters as the number of individuals per generation, crossover and mutation probabilities, selection strategies and, mainly, the fitness function. 
Optimisation of Electric Field Uniformity in Microwave Heating Systems by means of Multi-feeding and Genetic Algorithms

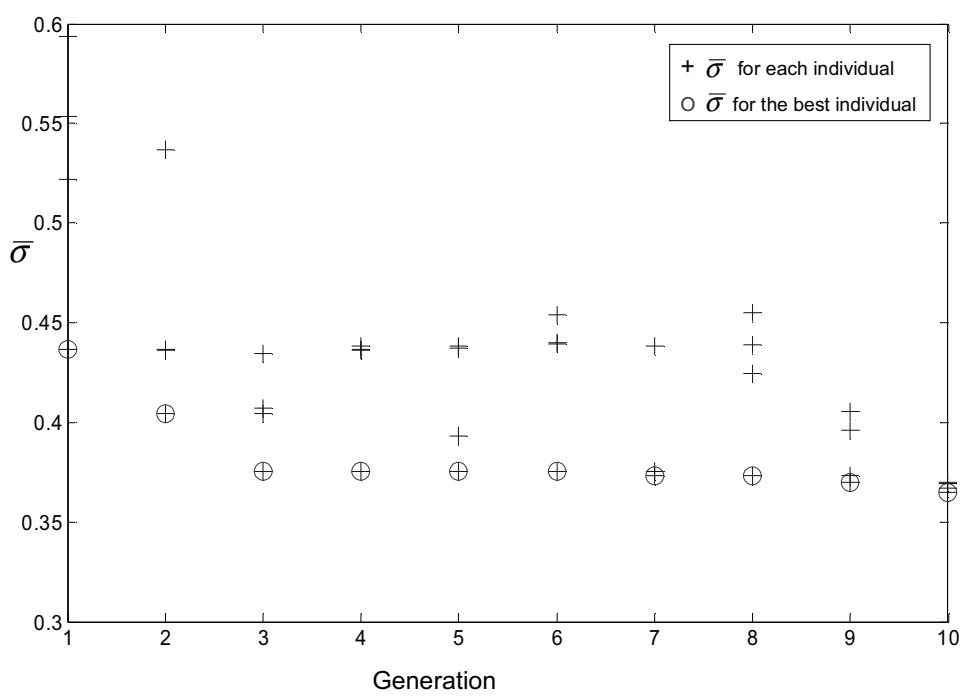

Figure 8. GA evolution for one-guide feeding design.

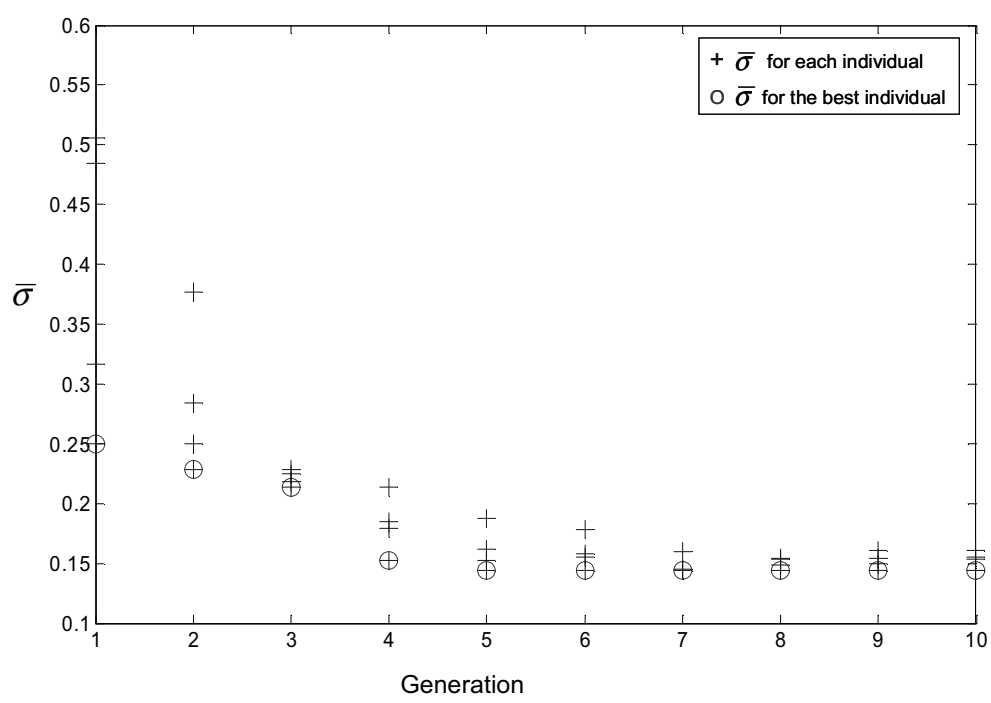

Figure 9. GA evolution for four-guides feeding design.

As regards to the slotted waveguide configuration, Figure 10 shows the final design for five slots, and the electric field distribution for this design is presented in Figures $11(z=0), 12(x=0)$ and 13 (epoxy resin upper surface plane). Since this is a $3 \mathrm{D}$ scenario, the results are not comparable 
E. Domínguez-Tortajada, P. Plaza-González, A. Díaz-Morcillo, J.V. Balbastre

with those of the multiple waveguide feeding. Nevertheless, the optimisation evolution, presented in Figure 14, shows the same behaviour than the previous ones with a correct convergence of the individuals to the best solution. In order to compare the performance of the GA when the number of slots increases, a 10 slots configuration has been optimised Comparing the results for 5 and 10 slots (Table 2), a slight improvement in the uniformity of electric field and a reduction of the electric field strength when the number of slots is increased become apparent.

Table 2. Statistical results for slotted waveguide feeding

\begin{tabular}{|c|c|c|c|}
\hline Configuration & $\begin{array}{c}\text { Norm. standard } \\
\text { deviation }\end{array}$ & $\begin{array}{c}\text { Electric field } \\
\text { mean }\end{array}$ & $\begin{array}{c}\text { Computational } \\
\text { times }\end{array}$ \\
\hline Five slots & 0.18 & $155.99 \mathrm{~V} / \mathrm{m}$ & $534 \mathrm{~min}$. \\
\hline Ten slots & 0.15 & $127.75 \mathrm{~V} / \mathrm{m}$ & $1558 \mathrm{~min}$. \\
\hline
\end{tabular}

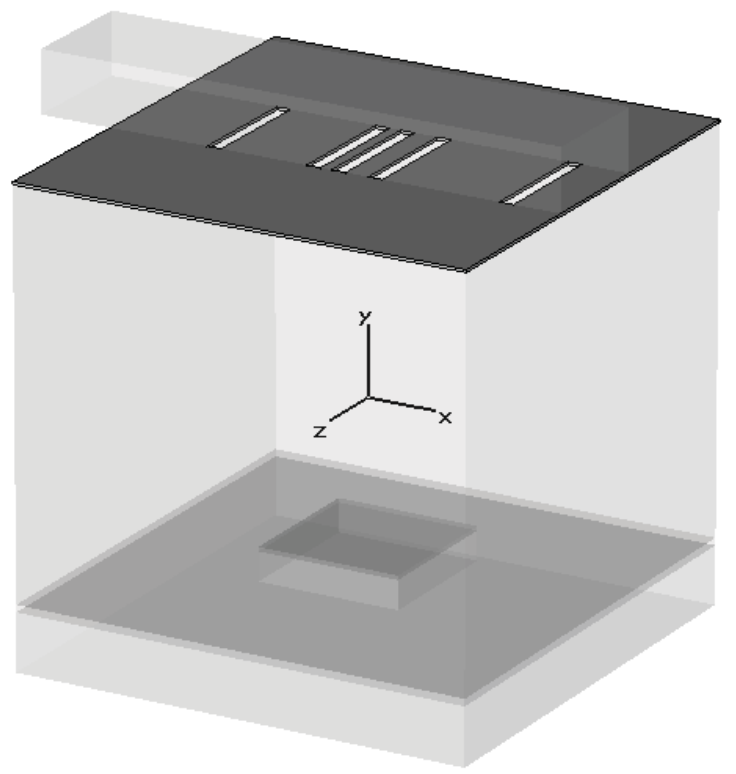

Figure 10. Final design for slotted waveguide (5 slots) 
Optimisation of Electric Field Uniformity in Microwave Heating Systems by means of Multi-feeding and Genetic Algorithms
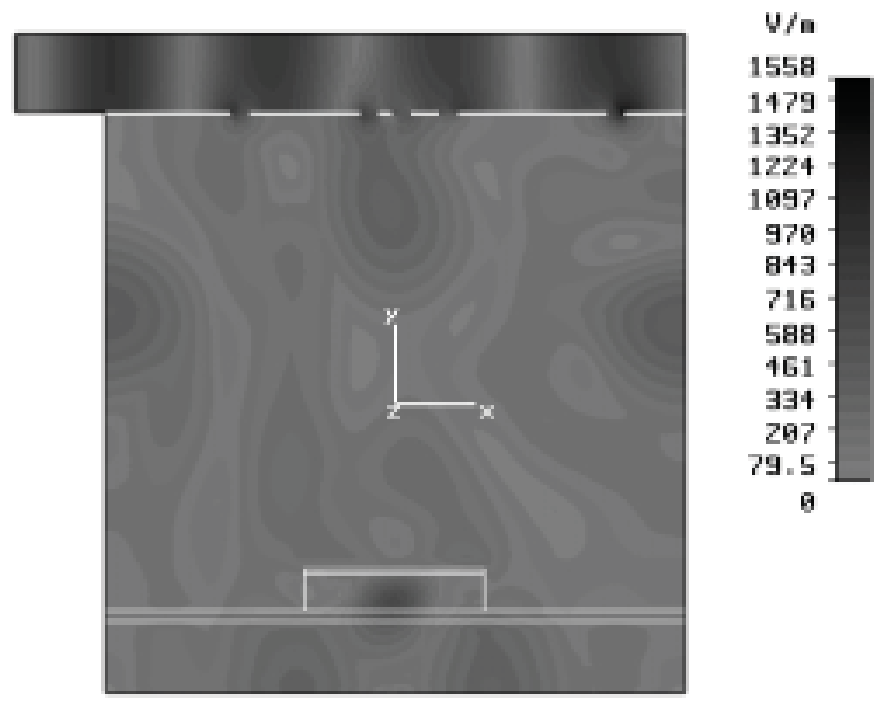

9

Figure 11. Electric field distribution for slotted waveguide (5 slots). $Z=0$ plane $\left(X_{1}=-14.712 \mathrm{~mm}, X_{2}=-87.98 \mathrm{~mm}, X_{3}=6.9331 \mathrm{~mm}, X_{4}=-73.32\right.$ $\mathrm{mm}, X_{5}=123.78 \mathrm{~mm}$.)

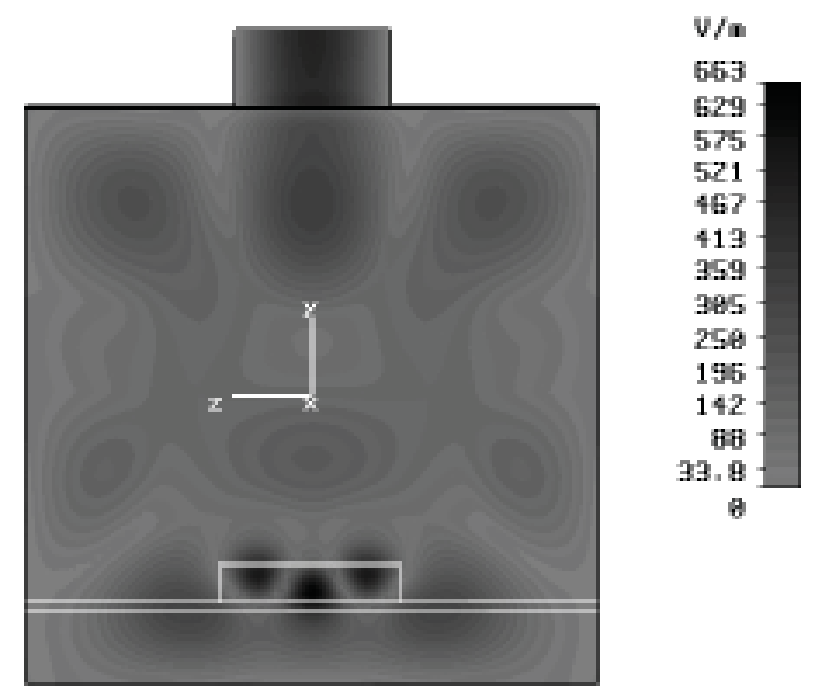

Figure 12. Electric field distribution for slotted waveguide (5 slots). $X=0$ plane 
E. Domínguez-Tortajada, P. Plaza-González, A. Díaz-Morcillo, J.V. Balbastre
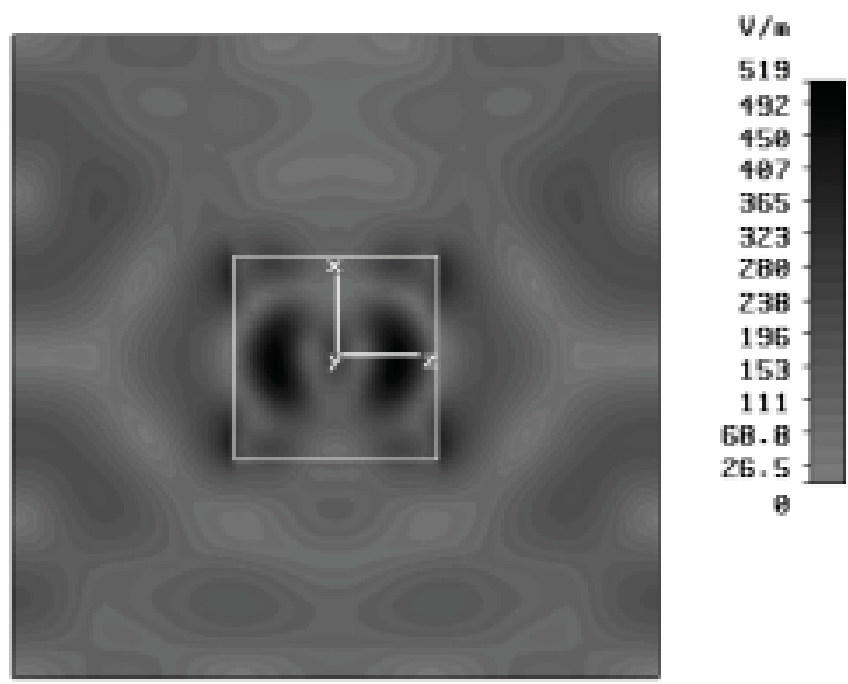

Figure 13. Electric field distribution for slotted waveguide (5 slots) on the upper surface of epoxy resin

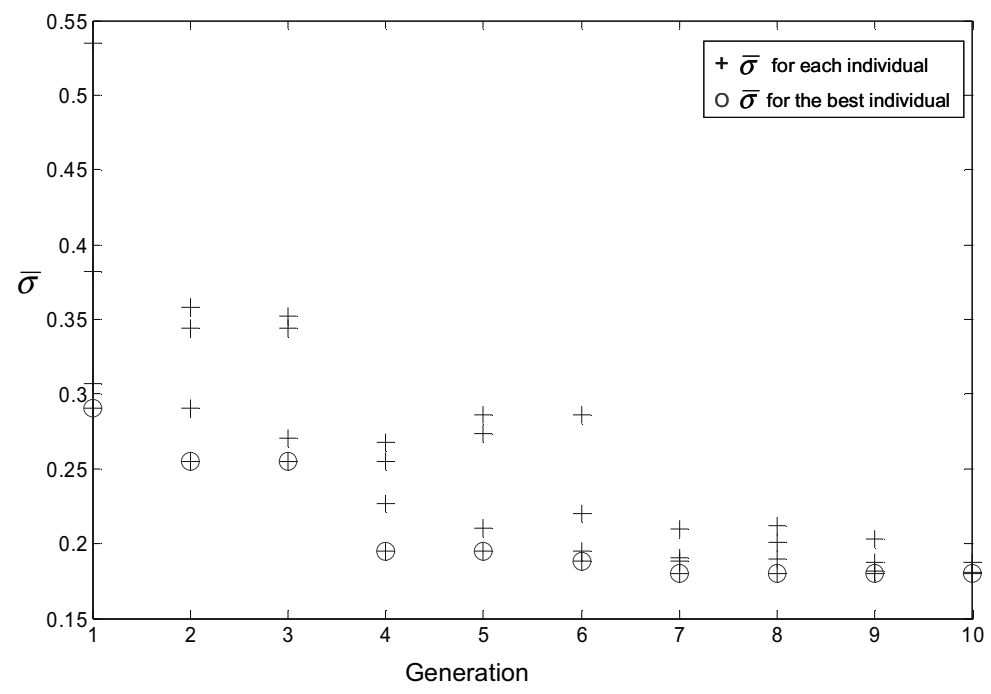

Figure 14. GA evolution for slotted waveguide (5 slots) design. 
Optimisation of Electric Field Uniformity in Microwave Heating Systems by means of Multi-feeding and Genetic Algorithms

\section{Conclusions}

In this work an optimisation technique for obtaining electric field uniformity over a given material by means of a proper design of the feeding system has been described and the results for a real - world application, as the curing of epoxy resin over a marble surface, have been analysed. These results show that GA is a proper technique for this kind of electromagnetic problem, where different design parameters, i.e. the different positions of waveguides or slots, must be optimised. These parameters can be incremented incurring in more complex designs with, for instance, orientation of waveguides or orientation and thickness of slots or even allowing slotted waveguides at the six sides of the applicator. The results for both the 2D multiple waveguide feeding and the 3D slotted waveguide feeding prove that GA evolves up to a final design which is a global optimal solution.

The main computational tools for this procedure are the GA routines and the electromagnetic simulation which obtains the electric field distribution in the cavity and allows to calculate the fitness for each individual. The main computational cost is due to the electromagnetic simulation and, therefore, it is of the utmost importance to employ an efficient technique. A more analytic and efficient mode - matching technique could be implemented in order to reduce the computational cost of electromagnetic simulations and to allow a more intensive search in the solution space.

\section{Acknowledgements}

This work was supported in part by the CICYT, Spain, under project reference TIC 200405037-C02-02 and Consejería de Economía, Industria e Innovación, Región de Murcia, Spain, under the project reference 2I04SU063. 
E. Domínguez-Tortajada, P. Plaza-González, A. Díaz-Morcillo, J.V. Balbastre

\section{$\underline{\text { References }}$}

[1] A.C. Metaxas and R-J. Meredith (1983), Industrial Microwave Heating, Peter Peregrinus Ltd., London, pp 89-120.

[2] T.V. Chow Ting Chan and H.C. Reader (2000), Understanding Microwave Heating Cavities, Artech House, London.

[3] P. Plaza-Gonzalez, J. Monzó-Cabrera, J.M. Catalá-Civera and D. SánchezHernández (2003), 'A new Method for Analyzing Multimode-Microwave Heating Ovens with Mode Stirrers', $9^{\text {th }}$ International Conference on Microwave and High Frequency Heating, Loughborough.

[4] P. Plaza-González, J. Monzó-Cabrera, J.M. Catalá-Civera and D. SánchezHernández (2004), 'New Approach for the Prediction of the Electric Field Distribution in Multimode Microwave-Heating Applicators with Mode Stirrers', IEEE Transactions on Magnetics, vol. 40, n. 3.

[5] Y. Rahmat-Samii and E. Michielssen (1999), Electromagnetic Optimization by Genetic Algorithms, Wiley Series in Microwave and Optical Engineering, John Wiley and Sons, Inc.

[6] W. Wang, Y. Lu and J. S. Fu (2004), 'Arbitrary Planar Microwave Filter Design by the FEM-GA Approach', Microwave and Optical Technology Letters, Vol. 41, No. 4, pp:276-279.

[7] D. Suckley (1991), 'Genetic Algorithm in the design of FIR filters', IEE Proceedings G Circuits, Devices and Systems, pp: $234-238$.

[8] J. Pitarch, A.J. Canós, F.L. Peñaranda-Foix, J.M. Catalá-Civera and J. V. Balbastre (2003), 'Synthesis of Uniform Electric Field Distributions in Microwave Multimode Applicators by multifeed Techniques', $9^{\text {th }}$ International Conference on Microwave and High Frequency Heating, Loughborough.

[9] E. Domínguez-Tortajada, A. Díaz-Morcillo, J. Monzó-Cabrera, D. SánchezHernández (2003), 'Application of Genetic Algorithms in the Design of Multifeeding Cavities', $9^{\text {th }}$ International Conference on Microwave and High Frequency Heating, Loughborough.

[10] V.A. Mechenova and V.V. Yakovlev (2004), 'Efficiency Optimization for Systems and Components in Microwave Power Engineering', Journal of Microwave Power and electromagnetic Energy, Vol. 39, No. 1, 2004. pp: 15-29.

[11] K. Murphy and V.V. Yakovlev (2003), 'FDTD-Backed RBF Neural Network Technique for Efficiency Optimization of Microwave Structures', $9^{\text {th }}$ International Conference on Microwave and High Frequency Heating, Loughborough.

[12] C. R. Houck, J.A. Joines and M.G. Kay (1995), 'A Genetic Algorithm for Function Optimization: A MATLAB Implementation', NCSU-IE TR 95-09. 